\title{
Attitudes Towards Waste Minimisation Amongst Labour Only Sub-
}

\section{Contractors}

John Saunders, Higgins Construction and Peter Wynn, Department of Built

Environment, Anglia Polytechnic University, Chelmsford, UK (p.g.1.wynn@apu. ac.uk)

\section{Keywords}

Waste_management, waste_minimisation, attitude, sub-contractor

\begin{abstract}
Waste generation by the construction industry is a significant issue for the industry and for society generally. The paper examines previous studies of attitudes to waste management within the industry and by means of a small questionnaire study sets out to examine: the extent of labour only sub-contractors' awareness and understanding of waste as an issue, their perceptions of the causes of waste and their attitudes towards the allocation of financial responsibility for waste minimisation. The survey shows that the results of previous studies can be extended to labour only sub-contractors and it identifies a willingness, beyond what might have been anticipated for this group, to accept some of the costs of waste reduction.
\end{abstract}

\section{Introduction}

Waste generation by the UK construction industry is significant in terms of its direct cost to the industry itself and its relative contribution to the overall national waste burden. McGarth and Anderson (2000) reported that wastage rates within the industry may be as high as $10-15 \%$. Based on a commissioned survey, the Environment Agency (2001) estimated that construction and demolition waste accounted for 72.5 
million tonnes of the 470 million tonnes total for $1998-1999$. The large scale of construction waste has also been recognised as a problem in Australia (McDonald and Smithers (1998), Lingard et al (2000), Teo and Loosemore (2001)), the USA (Alexander (1993) and Helper (1994)) and Canada (Kalin, 1991)).

A characteristic of the U. K. construction industry is the large extent of labour only subcontracting, often on the basis of individual self-employed operatives. This paper is intended to contribute to discussion on how best to encourage such sub-contractors to reduce, recycle and segregate waste. It starts with a review of previous studies of attitudes towards waste minimisation. It then presents the results of a questionnaire survey of sub-contractors intended to ascertain:

- the extent of their awareness and understanding of waste as an issue for the industry;

- their attitudes to the causes of waste on site; and

- their attitudes to the financial implications of waste minimisation.

The results are then analysed to determine the extent to which the conclusions of previous research are applicable to such sub-contractors.

\section{Attitudes Towards Waste Minimisation}

Johnston and Mincks (1995) strongly advocated that waste reduction should be considered as a potential profit centre with the financial benefits distributed at all levels on site. However studies carried out in Hong Kong (Poon et al, 2001) concluded that financial incentives alone had little effect on waste sorting and that this could only be implemented through contractual terms or legislation. 
A number of researchers have tried to establish attitudes amongst operatives to waste minimisation on site. Teo et al (2000) stated that "the labour intensive nature of construction activity suggests that behavioural impediments are likely to influence waste levels significantly. " Lingard et al (2001) supported this, stating "the extent to which reduction, re-use and recycling of waste can be achieved depends, to a large extent, on motivational influences on the behaviour of construction workers. "

McDonald and Smithers (1998) attempted to reduce waste by the development of a waste minimisation culture among the workforce. They reported that "site operatives appeared to be highly motivated with regard to the waste management plan" with reductions of $15 \%$ in the volume of generated waste and $43 \%$ in waste sent to landfill. Lingard et al (2000) noted that operatives placed a higher importance on environmental issues than did managers who were more interested in cost, time and quality objectives. There were widely held perceptions among all categories of employee (operatives, site management and head office management) that:

- waste management is not cost effective; and

- company rewards for effective waste management are lacking.

This research was taken further by Lingard et al (2001) with a case study using goal setting and feedback. This found that under these conditions operatives were prepared to reduce waste by using materials more efficiently but were less inclined to sort and segregate waste. It was suggested that this was because of the effects on piece rate payments of the extra time this would require.

Surveys into operatives' attitudes to waste reduction, grounded in Ajzen's theory of planned behaviour (Ajzen, 1993) were carried out in Australia (Teo et al (2000), Teo 
and Loosemore (2001)). The research comprised an attitudinal survey followed by focus group discussions, the latter intended to explore the reasons behind associations identified by the survey. The key findings were:

- The ability of operatives to contribute to a waste reduction scheme was only as good as the level of management support offered. Operatives felt that a scheme could only be effectively carried out if it was given appropriate priority with the other project goals of time, cost and quality.

- Operatives lacked knowledge about the consequences of waste, what happened to it and the potential for reducing it. This is in contrast to the perceived high level of knowledge and involvement in waste management cited by Lingard et al (2000). However there was a strong desire for information concerning these issues.

- Operatives held negative perceptions of the recycling and / or reuse of materials, considering waste to be an inevitable by-product of construction activity: $68 \%$ of respondents felt a wastage level of about $10 \%$ was acceptable. This was despite the finding that $58 \%$ of respondents indicated relatively high levels of motivation to reduce waste.

- Even though cost savings prevailed as the primary motivating force for the adoption of waste reducing behaviour, the evidence presented suggested that, despite operatives' direct involvement with the materials being wasted, they perceive any potential cost benefits to be of little relevance to them.

The above studies, whilst agreeing on the importance of motivational influence, are divided on the most effective method of influence. Teo and Loosemore (2001) 
highlight the need for further attitudinal studies to waste management in differing contexts.

\section{Research Design and Methodology}

An attitudinal questionnaire was circulated to labour only sub-contractors paid on a piecework basis. Six UK construction sites, four in South Cambridgeshire and two in North London were visited in order to include sites at various stages of completion and hence representation of a broad range of trade sub-contractors. 50 questionnaires were issued and 46 were returned completed, a response rate of $92 \%$. Table I gives a summary of the trades of the respondents.

\section{[Take in Table I]}

The questionnaire was designed to address the following questions:

- How can sub-contractors best be motivated into participating fully in any waste minimisation programme?

- Do sub-contractors accept that levels of waste generation and waste reduction are issues that affect them?

- How can waste on site be reduced?

Propositions fell into the following categories:

- Five statements $(1,3,6,7$ and 17), the key objective of which was to explore the sub-contractors' awareness and understanding of waste as an issue for the industry and where they felt the onus for waste management should lie. Similar broad questions were included in the survey by Teo et al (2000).

- Six statements $(2,10,11,12,14$ and 15) designed to discover the subcontractors' awareness and understanding of the causes of waste identified by Skoyles and Skoyles (1987) and Guthrie and Mallet (1995) and to establish 
whether the operatives accepts that the causes and levels of waste are issues that affect them and whether they can be motivated to reduce waste.

- Six statements $(4,5,8,9,13$ and 16) to establish the sub-contractors' attitudes to any financial implications a waste reduction scheme may have.

Respondents were asked to respond on a 4 point Likert scale so as to force decisions on which side of neutral their feelings belong. The questions and a summary of responses are shown in Figure 1.

[Take in Figure 1]

\section{Results for Individual Propositions}

The reactions to the statements summarised in Figure 1 are here discussed and interpreted individually. A subsequent section will examine the attitudes revealed in a broader setting. Comparisons are made with previous similar research.

\section{Q1 The industry should be doing more to reduce waste}

The $91 \%$ agreeing or strongly agreeing with the statement indicates that waste is generally perceived by operatives as a problem within the industry. It should however be pointed out that it is no more than a broad sweep statement and agreement with it has probably been made without thought to implications of cost or the required changes in work practice. This response reinforces the survey by Teo et al (2000) where $88 \%$ of respondents felt that recycling was possible on site and 53\% agreed with the proposal for waste management practices on site.

Q2 The quality of site management is the main factor affecting levels of waste produced on site 
$74 \%$ of respondents agreed or strongly agreed with this statement. Two interpretations are possible. Firstly sub-contractors may consider main contractor management support and encouragement to be lacking in terms of such matters as positioning of skips, goal setting and feedback. This supports both Lingard et al (2000) whose operative survey found "management supportiveness of waste management" was the major issue to affect waste levels on a construction site and Teo et al (2000) who concluded "The ability of operatives to contribute to waste reduction activities is dictated largely by managers interest in waste management and their willingness to commit resources to it. "A second interpretation is that the respondents simply considered how well a site was managed by the main contractor in terms of such matters as materials storage and ordering of correct materials. This is an equally valid factor affecting levels of waste production.

Q3 A wastage level of about $10 \%$ is an acceptable by-product of the construction process

$71 \%$ agreed or strongly agreed with this statement. Teo et al (2000), who also asked about acceptable wastage levels, found that $58 \%$ of their respondents felt a wastage level of between $1 \%$ and $10 \%$ to be acceptable and $31 \%$ considered a level between $11 \%$ and $20 \%$ to be acceptable. Clearly both surveys indicate a high tolerance of wastage amongst operatives in the industry.

Q4 The main contractor should bear full responsibility for ensuring all waste on site is segregated

$85 \%$ of all respondents felt that the main contractor should bear the full responsibility with $46 \%$ strongly agreeing., the largest "strongly agreeing" response in the survey. 
The large positive response to the survey suggests that whatever else the sub-contractors may feel about waste management, they do not feel that primary responsibility lies with themselves. Waste segregation is a fundamental part of any waste management programme. To achieve a successful outcome it is essential to have commitment of the operatives. Clearly this could be difficult if waste management is seen as someone else's problem.

\section{Q5 Sub-contractors should sort and segregate waste as a matter of course}

Questioning is again aimed at seeking sub-contractors' attitudes on where responsibility for waste management should lie. This time the suggestion implied a change in working practice from the norm for those being surveyed. 54\% of respondents disagreed or strongly disagreed with the proposition. To some extent the fact that $46 \%$ agreed or strongly agreed indicates that, in spite of the strong feeling in response to the preceding statement that primary responsibility should lie with the main contractor, there is a reasonable pool of sub-contractors who would be willing to co-operate in waste management.

\section{Q6 Waste minimisation will be a major issue for sub-contractors in the future}

$85 \%$ agreed or strongly agreed with the statement. This perhaps links with the response to Statement 1 where $91 \%$ agreed that the industry should be doing more to reduce waste and suggests that there is an expectation that there will be pressures for change in the waste performance of the industry.

Q7 The Government should increase the landfill tax to force waste reduction on site 
$44 \%$ agreed or strongly agreed that the Government should increase the Landfill Tax in an effort to force waste reduction on site. The $24 \%$ strongly agreeing suggests a large minority of the respondents feel that the issue of waste reduction needs radical action at government level. The majority however disagree or strongly disagree with the statement. It is interesting to compare this with the responses to Statement 1 where there is overwhelming support for the proposition that the industry itself should take action to reduce waste.

Q8 Sub-contractors should be expected to price for the costs involved in waste reduction

$46 \%$ of the respondents agreed with the statement and $54 \%$ disagreed. The $18 \%$ strongly disagreeing is the second highest "strongly disagree" result in the survey and probably reflects the realisation that there may be financial pressures placed on them.

\section{Q9 Sub-contractors should be penalised financially for waste produced on site}

This statement is similar to Statement 8 but is stronger. $75 \%$ either disagreed or disagreed strongly with the proposition. This figure, and particularly the $24 \%$ strongly disagreeing, is again likely to reflect the realisation of a direct financial impact on themselves. This would be made worse by the potential open-ended nature of the penalty.

Q10 Poorly off-loaded and incorrectly stored materials are the major causes of wastage on site

This is one of a series of statements exploring sub-contractors' opinions as to why waste may occur on site. $83 \%$ agreed or strongly agreed with the proposition with a high 
proportion (37\%) strongly agreeing. From observation Skoyles and Skoyles (1987) identified this area as one of the major causes of site wastage. Waste generated in this way tends to be on a large scale and is often clearly visible to operatives. It tends to stay in operatives minds as a large scale problem and acts as a disincentive for individual effort to reduce waste.

\section{Q11 Poor design resulting in excessive off-cuts is the major cause of wastage on site} $66 \%$ of respondents felt that poor design is the major cause of wastage. Of these only $17 \%$ strongly agreed, a figure much less than those who strongly agreed that poor offloading and storage are the major cause. In practice it is likely to be difficult for the sub-contractors to establish whether the design itself is responsible for the waste. It is possible for example that an alternative design, considered less wasteful by a subcontractor, may produce more waste elsewhere in the process.

\section{Q12 Lack of care by sub-contractors is the major cause of wastage on site}

This proposition forces the sub-contractors to consider their own approach to work. It brings into full focus the issue of working methods and the emphasis on production rather than quality. A number of previous studies, for example Johnstone and Mincks (1995), Poon et al (2001), Lingard et al (2001), suggest that this issue is a major factor in operatives' attitudes to waste reduction. 58\% agreed with the proposition with a perhaps surprising $18 \%$ strongly agreeing. Conversely $42 \%$ disagreed or disagreed strongly, the highest negative response within the survey. Teo et al (2000) included a similar proposition within their survey, finding only $11 \%$ of operatives accepting their lack of care as the major cause. 
Q13 Main contractors should factor in allowable waste percentages to subcontractors' packages, with financial penalties payable above agreed levels

This brings together the issues of costs and possible penalties into a single proposition. This approach is becoming more popular (Guthrie and Mallet, 1995). 56\% of respondents agreed with the statement whilst $44 \%$ disagreed. This can be compared with the $75 \%$ who disagreed with the open-ended penalty provision of Statement 9 and indicates a level of acceptance that there should be shared financial responsibility for waste between main and sub-contractors.

Q14 Purchasing of materials by sub-contractors would reduce the level of wastage on site

$50 \%$ agree and $22 \%$ strongly agree with this proposition. It suggests that there is a perception that if materials are provided by the main contractors there is little incentive for sub-contractors to avoid wastage. It can be argued that if the sub-contractor viewed the materials as a "profit centre" there would be less emphasis on piece-work and an increased emphasis on "right first time".

\section{Q15 Education of sub-contractors is the preferred method of reducing site wastage}

Studies, by for example McDonald and Smithers (1996) and Lingard et al (2000), have shown operatives to have only limited knowledge about general waste issues. The perceived need for education is difficult to evaluate and it can be questioned whether greater knowledge of issues such as global warming would make operatives more responsive to waste management. However McDonald and Smithers (1996) found in their study that operatives who had undergone training and induction were highly motivated and noted an associated reduction in waste levels. 
This statement in the present survey is intended to obtain an insight into attitudes of sub-contractors on education and its role, if any, in helping to reduce waste. $63 \%$ of sub-contractors agreed with the proposition. This is comparable with Teo et al (2000) who noted that $63 \%$ of operatives who had undergone training found it to be useful.

Q16 Levels of waste will not be reduced until it is financially beneficial to the subcontractor to do so.

This proposition seeks to establish whether a financial incentive is a requirement for waste reduction. $\quad 67 \%$ agreed or strongly agreed with the statement indicating that finance is the major motivating factor. This reinforces previous studies by Teo and Loosemore (2001) and Lingard et al (2000) and indicates that other measures such as education will not be successful on their own in reducing waste and that either the approach of sharing financial benefits advocated by Johnstone and Mincks (1995) or the use of financial penalties, explored in earlier propositions in the current survey, will be required.

Q17 The main contractor should employ operatives to sort and segregate waste on site

Not surprisingly $83 \%$ of respondents agreed with this proposition with a large number strongly agreeing. It appears to absolve the sub-contractors of any responsibility for waste control and does not impact on their work methods other than perhaps encouraging more waste in the knowledge that someone else will clear it away.

\section{Discussion of Issues Revealed by the Survey}

Sub-contractors' Awareness and Understanding of Waste as an Issue for the Industry 
(Propositions 1, 3, 6, 7, and 17)

Responses to Propositions 1, 6 and 7 show there is without doubt an awareness of waste as an issue the industry will need to address. Despite this awareness, sub-contractors appeared prepared to accept waste levels of the order of $10 \%$. Sub-contractors showed a strong preference for the main contractor to have responsibility for sorting and segregating waste. This suggests that even though sub-contractors are aware of the issue, they are more than happy to continue generating current levels of waste.

The response to Proposition 17 indicates sub-contractors are generally content to leave physical sorting and segregation of waste to the main contractor, allowing them to continue at current waste levels, maintain output and effectively ignore the waste issue. In the worst case the sub-contractor may produce more waste in the knowledge that someone else will clear it up.

The response to Proposition 8 indicates a substantial minority feel the Government should increase landfill taxation, possibly feeling that this will not directly impact on sub-contractors themselves.

\section{Sub-contractors' Attitudes on Causes of Waste}

(Propositions 2, 10, 11, 12, 14 and15)

Both Skoyles and Skoyles (1987) and Guthrie and Mallet (1995) have highlighted the subjects of these propositions. They are quality of site management, poorly off-loaded and stored materials, poor design, lack of care by operatives and lack of educational awareness of waste issues. As with previous studies in this area, the results are not conclusive and are open to various interpretations. 
Not surprisingly sub-contractors perceived their lack of care as the least likely reason of those offered for waste to be produced on site. Although even here a substantial number accepted this as a major cause.

The other options had a higher level of acceptance. $63 \%$ of respondents felt education was the preferred method of reducing waste. This high level of agreement with the proposition was surprising for a number of reasons. The type and duration of any educational process was not mentioned. There is an implication, perhaps not realised by the respondents, that education will reduce production time and result in a drop in income. It is however encouraging that sub-contractors are keen to use education to improve their working practices.

Poorly off-loaded and stored materials was the proposition that generated most agreement. This may be primarily due to the number of high profile examples subcontractors see on site, for example uncovered pallets of plaster ruined as a result of exposure to the elements. Poor design or the quality of main contractor management do not necessarily produce such visible effects. The trickle effect is also less noticeable: the daily wastage of half a bag of cement can soon amount to a full pallet of wastage.

Attitudes to Where Responsibility for Waste Management Should Lie

\section{Propositions 4, 5, 8, 9, 13 and 16}

The response to Proposition 4 indicated a feeling that the responsibility, and hence the financial burden of waste management should lie with the main contractor. To some 
extent this is contradicted by the response to Proposition 5 where $46 \%$ accepted subcontractor responsibility for waste segregation. The responses to Propositions 8 and 13 show some willingness to accept that sub-contractors should take some financial responsibility for waste reduction, though the acceptance is vastly reduced when the word penalty is introduced in Proposition 8. Apart from the very large response in favour of Proposition 4, many of the responses to this group of propositions tend to support Teo et al (2000), Lingard et al (2000) and McDonald and Smithers (1998) in their findings that the attitude to waste reduction is generally positive.

\section{Conclusions}

The survey has shown a general awareness of the issue of waste management amongst labour only sub-contractors in the construction industry, an acceptance that the industry should be doing more to reduce waste and a realisation that the area will become more of an issue for such sub-contractors. However this is contradicted by a continued acceptance of current levels of wastage and an attitude that all responsibility for waste management should lie with the main contractor.

Sub-contractors consider the main cause of waste to be poorly off-loaded, and storage of, materials although poor design was also accepted as a major cause. Of the options for causes of wastage offered, they considered their own workmanship to be the least likely cause, although it was still recognised by the respondents as a major cause of waste. There was a surprisingly high agreement that education of sub-contractors was an important factor in reducing site wastage. 
Much of the previous research in this area suggests that, despite generally positive attitudes to the need for waste management, cost prevailed as the primary motivating factor. The current investigation shows that there is willingness for labour-only subcontractors to carry some of these costs but that there should also be equitable sharing of benefits arising from the treatment of waste management as a profit centre.

The authors acknowledge the relatively small sample size of their survey and accept that a larger scale study would be required to validate their findings.

\section{References}

Alexander, J. (1993) “Making Job-Site Recycling Work”, Journal of Light Construction, Vol. 12, No. 2, pp 28-29.

Ajzen, I. (1993) “Attitude Theory and the Attitude - Behaviour Relation” in Krebs, D. and Schmidt (eds) New Directions in Attitude Measurement, Walter de Gruyer, Berlin, pp 41-57.

Environment Agency (2001) Construction and Demolition Waste Survey R\&D Technical Summary PS368, Environment Agency, Swindon.

Guthrie, P. and Mallett, H. (1995) Waste Minimisation and Recycling in Construction, Special Publication 122, CIRIA, London.

Helper, H. (1994) “Construction and Demolition Waste Recycling: Raising Consciousness", American City and County, Vol. 109, No. 1, pp 32-42.

Johnston, H. and Mincks, W. R. (1995) “Cost Effective Waste Minimisation for Construction Managers", Cost Engineering, Vol. 37, No. 1 pp 31-39.

Kalin, Z. (1991) “Canada Targets Construction and Demolition Waste”, Biocycle, Vol. 32, No. 1, pp 35-36. 
Lingard, H., Graham, P. and Smithers, G. (2000) "Employee Perceptions of the Solid Waste Management System Operating in a Large Australian Contracting Organization: Implications for Company Policy Implementation, Construction Management and Economics, Vol. 18, No. 4, pp 383-393.

Lingard, H., Gilbert, G and Graham, P. (2001) "Improving Solid Waste Reduction and Recycling Performance Using Goal Setting and Feedback”, Construction Management and Economics, Vol. 19, No. 8, pp 809-817.

McDonald, B and Smithers, M (1998), "Implementing a Waste Management Plan During the Construction Phase of a Project: a Case Study", Construction Management and Economics, Vol. 16, No. 1, pp 71-78.

McGarth, C. and Anderson, M (2000) Waste Minimisation on a Construction Site: Digest 447, Building Research Establishment, London.

Poon, C. S., Yu, A. T. W. and Ng, L. H. (2001) “On-site Sorting of Construction and Demolition Waste in Hong Kong”, Resources, Conservation and Recycling, Vol. 32, No. 2, pp 157-172.

Skoyles, E. R. and Skoyles, J. (1987) Waste Prevention on Site, Mitchell Publishing Company, London.

Teo, M. M. M., Loosemore, M., Masosszeky, M. and Karim, K. (2000) “Operatives Attitudes Towards Waste on a Construction Project", Annual Conference ARCOM 2000, Volume 2, pp 509-517.

Teo, M. M. M. and Loosemore, M. (2001) "A Theory of Waste Behaviour in the Construction Industry", Construction Management and Economics, Vol. 19, No. 7, pp 741-751. 